\title{
Digital phenotyping of winter squash fruits
}

R. Machado Junior ${ }^{1}$, R.S. Gomes ${ }^{2}$, C.F. de Almeida ${ }^{1}$, V.Q. Carneiro ${ }^{3}$, R.L. de Oliveira ${ }^{3}$, R.D.F. Laurindo ${ }^{2}$, G.M. Maciel $^{4}$ and D.J.H. da Silva ${ }^{2}$

${ }^{1}$ Departamento de Genética e Melhoramento, Universidade Federal de Viçosa, Viçosa, MG, Brasil

${ }^{2}$ Departamento de Fitotecnia, Universidade Federal de Viçosa, Viçosa, MG, Brasil

${ }^{3}$ Departamento de Biologia, Universidade Federal de Lavras, Lavras, MG, Brasil

${ }^{4}$ Instituto de Ciências Agrárias, Universidade Federal de Uberlândia, Monte Carmelo, MG, Brasil

Corresponding author: R. Machado Junior

E-mail: ronaldo.juniior@ufv.br

Genet. Mol. Res. 19 (3): gmr18646

Received March 24, 2020

Accepted August 31, 2020

Published September 30, 2020

DOI http://dx.doi.org/10.4238/gmr18646

ABSTRACT. Winter squash (Cucurbita moschata) has great importance as a food. Brazil has a wide genetic variability of squash; most of this is conserved in germplasm banks. The Vegetable Germplasm Bank of the Federal University of Viçosa (BGH-UFV) includes more than 350 accessions of squash; however, this germplasm is still little used. Characterization of accessions requires time, labor, and financial resources. Image-based, high-quality and large-scale phenotyping is a promising alternative tool. We propose digital phenotyping of $C$. moschata germplasm fruit. To achieve this, we evaluated 466 fruits from 148 accessions of squash from BGH-UFV and four checks. After longitudinal cutting, the fruits were evaluated on the basis of their length, diameter, and internal cavity dimensions. An image of every fruit was also obtained. Digital measurements were made using the software FENOM. The comparison between manual and digital forms of fruit evaluation was carried out with the software GENES. The comparisons were based on the analyses of simple linear regression, bias, the coefficient of Pearson correlation, the index of concordance, the index of performance, the efficiency of the method, the absolute average error, and the absolute maximum error. The evaluations based on images had high concordance $(>0.93)$, almost perfect correlation $(>0.99)$, and a 
performance classified as excellent $(>0.92)$, in the evaluation of all the descriptors, when compared to manual measurements. We conclude that phenotyping of winter squash fruits based on digital images is promising for the characterization of $C$. moschata accessions, resulting in an efficient evaluation.

Key words: Phenomics; Characterization; Cucurbita moschata

\section{INTRODUCTION}

Winter squash is a vegetable/fruit with high socioeconomic significance, as it is used for several purposes in industry, as feeding and in medicine (Resende et al., 2013; Oliveira et al., 2016; Machado Junior et al., 2017; Gomes et al., 2020a). Brazil is an important holder of the genetic variability of C. moschata (Ferreira et al., 2016; Gomes et al., 2020a; Gomes et al., 2020b). Around 2,700 accessions are preserved ingermplasm banks. The Vegetable Germplasm Bank at Federal University of Viçosa (BGH-UFV) maintains 400 accessions of this species (Silva, 2001). However, much of this germplasm has not been characterized yet, due to the large numbers and onerosity of manual evaluation. The complexity of manual germplasm characterization has also made it difficult to select germplasm as potential parents for crosses as well as or selection of promising segregating populations.

Despite the simplicity of this traditional technique, it requires time, labor, and financial resources, along with high potential for experimental errors. The evaluation of plant germplasm through images is potentially a more accurate and faster alternative than traditional techniques. The shape of the fruit has been widely studied (Fischer et al., 2015; Fischer et al., 2016; Priori et al., 2018). This fact demonstrates the relevance in the search for new optimizing alternatives.

Several studies have shown the potential use of digital images to characterization, identification, classification and grading of fruits (Behera et al., 2020). There are reports of the success in passion fruit's (Sidehabi et al., 2018), persimmon (Maeda et al., 2018), papaya (Cortes et al., 2017), tomatoes (Zaborowicz et al., 2017), orange (Rashidi et al., 2009), melon (Khojastehnazhand et al., 2009), watermelon (Koc, 2007), etc. However, digital imaging techniques to characterize winter squash germplasm have not been reported.

Based chiefly on the use of images, the term 'phenomics' has been associated with the optical analysis of plant characteristics (Walter et al., 2015). This methodology provides a large amount of data in a relatively short period of time compared with conventional methods (Sousa et al., 2015), besides allowing image data storage for future use. The evaluation of winter squash germplasm based on images is still sparsely explored. Thus, our objective is to promote digital phenotyping of winter squash germplasm fruits. The objective of this work was to test the use of digital phenotyping to characterize winter squash fruits.

\section{MATERIAL AND METHODS}

The experiment was conducted at the Federal University of Viçosa, Minas Gerais, Brazil (200 45'14"' S, 420 52'53'" W e 648,74 m), from January to July 2017 . We 
evaluated 148 accessions of $C$. moschata kept in the BGH-UFV, commercial hybrids Tetsukabuto and Jabras, and cultivars Jacarezinho and Maranhão, totaling 466 fruits. This germplasm was also evaluated in terms of morphoagronomic and nutritional variability by Gomes et al. (2020b). Fruits were cut longitudinally and evaluated for length (LF) and diameter (DF) as determined by longitudinal and transverse measurements, respectively; and length (LIC) and diameter of internal cavity (DIC) as determined by longitudinal and transverse measurements of internal cavity, respectively (Figure 1).

A

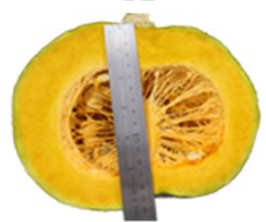

B

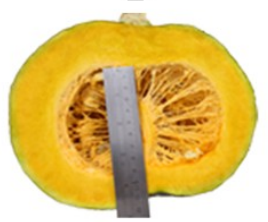

C

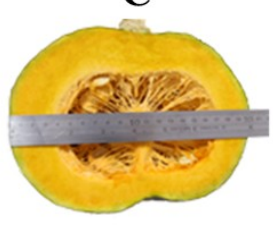

D

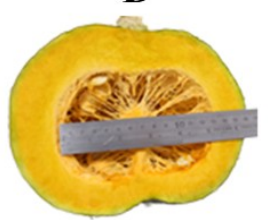

Figure 1. Manual measurement of winter squash fruits: (A) length of fruit (LF); (B) diameter of fruit (DF); (C) length of internal cavity (LIC); (D) diameter of internal cavity (DIC).

After identification, fruits were submitted to manual evaluation and photographed. A photographic studio with adequate dimensions was built to obtain high quality and standardized images. The studio was comprised of a structure in the format of a cube and had a capacity of $1.0 \mathrm{~m}^{3}$ (Figure 2). The superior part and a section of the lateral part of the studio with dimensions $0.9 \times 0.7 \mathrm{~m}$ was kept open. The lateral part was covered with a failete-white fabric for diffusing light. Reflectors with led lamps $(12 \mathrm{w})$ were placed opposite to the lateral section. Reflectors were set up on a base $0.3 \mathrm{~m}$ high at a 90 -degree angle and $0.5 \mathrm{~m}$ from the studio, allowing a uniform distribution of light in all directions and preventing shadow formation.
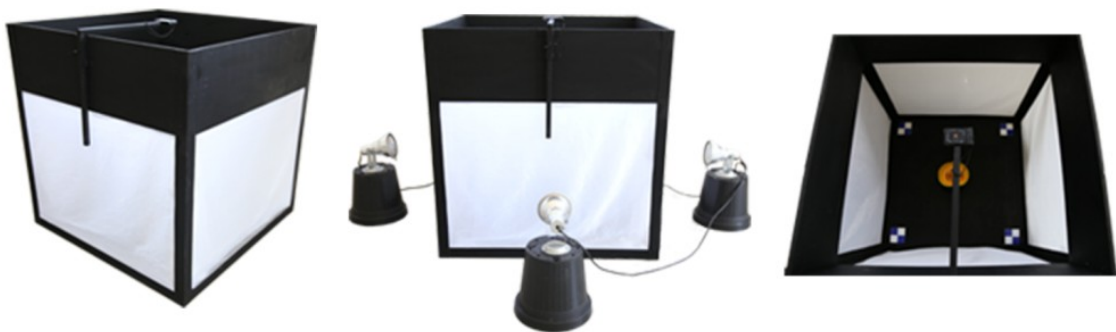

Figure 2. Studio used for the acquisition of images of winter squash fruits for morphoagronomic characterization.

The lower surface of the studio had a dimension of $1.0 \mathrm{~m}^{2}$ and was painted black. Reference images on a blue-white grid, with dimensions $10 \times 10 \mathrm{~cm}$, were set in four lower corners of the studio (Figure 3.A). The three-dimensional representation of this studio is available at www.fenomica.com.br. The reference images (Figure 3.B) were used to identify the dimensions of every pixel in the images. With this information, a pixel-to-distance conversion factor was determined. The conversion factor was $0.0269 \mathrm{~cm}$ and was used to calculate the actual distance between two points on the fruit represented in the image. 
A

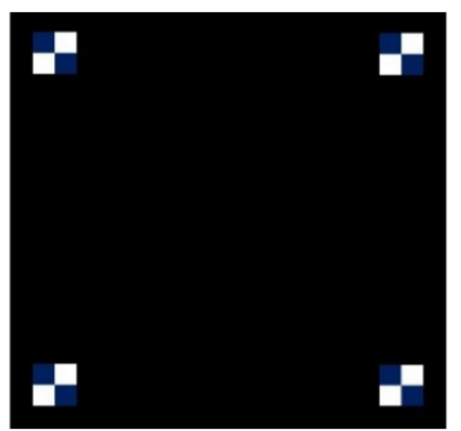

B

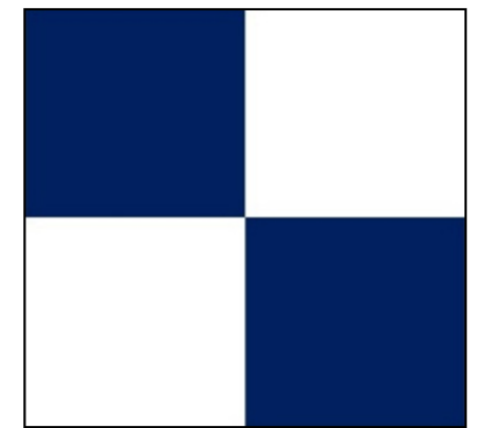

Figure 3. Studio's details used to acquire the digital images of fruits for morphoagronomic characterization: ALower surface of the studio used for the acquisition of images. B- Reference image used in the lower surface of the studio.

A digital camera (Sony Cyber-Shot DSR-WX350) was used for acquisitions. The camera resolution was standardized with ISO 100, F 3.5, size 3664 × 3664 pixels, resolution 350 x 350 dpi, 24-bit intensity, flash off, and sRGB color representation. The images were saved in JPEG format. The fruits were positioned in the center of the camera's view field and the camera was affixed $1 \mathrm{~m}$ from the lower surface of the studio.

Imagens were assessed using FENOM software, developed with the help of the library of digital processing of images of MATLAB, available at www.fenomica.com.br. This software relied on procedures for real-time acquisition, preprocessing, segmentation, and measurement of images. In this study, we used the procedure of measuring distances between points established by the user (Figure 4).

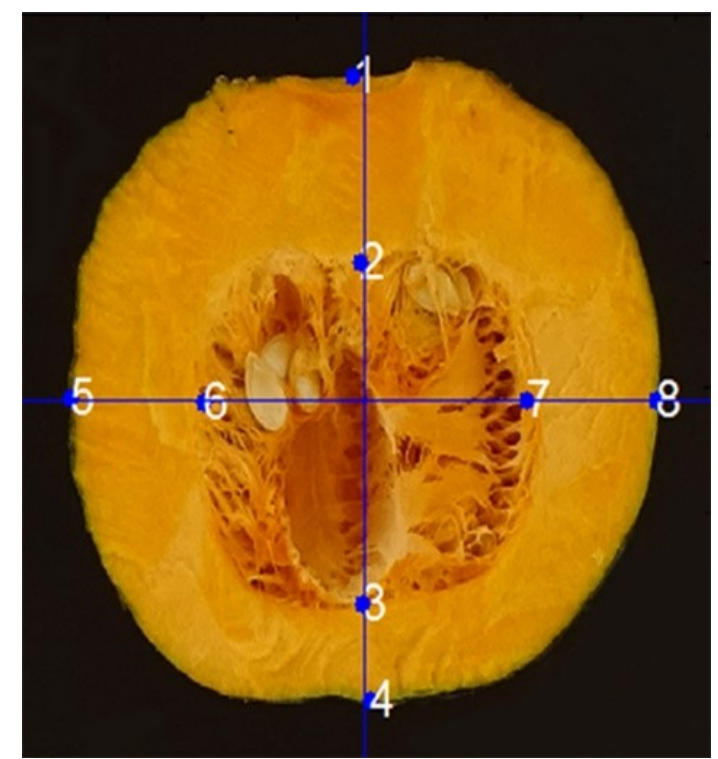

Figure 4. Digital assessment of the fruit: Length of fruit (segment from point 1 to 4); diameter of fruit (segment from 5 to 8); length of internal cavity (segment from 2 to 3); diameter of internal cavity (segment from 6 to 7 ). 
The time spent was timed in both types of evaluation, where each fruit represents an experimental unit and the treatments were the two methods of phenotyping. The measurements obtained manually and those obtained from the digital images were compared to evaluate the efficiency of phenotyping across methods. This comparison was made with the help of the software for analysis in experimental statistics - GENES [version 1990.2018.17(Cruz, 2013)]. The following reliability measures were adopted:

(i) Angular coefficient $(\beta)$ and coefficient of determination $\left(\mathrm{R}^{2}\right)$ of the simple linear regression, model:

$$
Y=\beta X+e
$$

where: $\mathrm{Y}$ is the value obtained from the image analysis, $\beta$ is the angular coefficient, and $\mathrm{X}$ corresponds to the values obtained from the manual measurement. The $\beta$ value was tested by the $t$ test, with $\alpha \leq 0.05$, whose hypotheses were: $H_{0}: \beta=1$ and $H_{a}: \beta \neq 1$

(ii) Bias

$$
\text { Bias }=(\hat{\beta}-1)
$$

(iii) The correlation of Pearson

$$
(r)=\frac{\sum_{i=1}^{n}\left(X_{i}-\bar{X}\right) *\left(Y_{i}-\bar{Y}\right)}{\sqrt{\sum_{i=1}^{n}\left(X_{i}-\bar{X}\right)^{2}} * \sqrt{\sum_{i=1}^{n}\left(Y_{i}-\bar{Y}\right)^{2}}}
$$

where $\mathrm{n}$ corresponds to the number of fruits evaluated; corresponds to the ith value obtained with manual measurement; represents the $i$ th value observed from the image analysis; corresponds to the average values obtained by manual measurement; and to the average values observed from the image analysis. The classification of the correlation of Person proposed by Hopkins (2000) is presented in Table 1.

Table 1. Classification of the coefficient of correlation of Pearson (r), proposed by Hopkins (2000).

\begin{tabular}{ll}
\hline Coefficient of correlation "r" & \\
\hline 0.0 to 0.1 & Classification \\
0.1 to 0.3 & Very low \\
0.3 to 0.5 & Low \\
0.5 to 0.7 & Moderate \\
0.7 to 0.9 & High \\
0.9 to 1.0 & Very high \\
\hline
\end{tabular}

(iv) Concordance index proposed by Willmott et al. (1985)

$$
d=1-\frac{\sum_{i=1}^{n}\left(X_{i}-Y_{i}\right)^{2}}{\sum_{i=1}^{n}\left(\left|Y_{i}-\bar{X}\right|+\left|X_{i}-\bar{X}\right|\right)^{2}}
$$

(iv) Performance index proposed by Camargo and Sentelhas (1997)

$$
c=r * d
$$

whose criteria of interpretation are presented in Table 2. 
Table 2. Criteria of interpretation of the performance index "c" proposed by Camargo and Sentelhas (1997).

\begin{tabular}{ll}
\hline Values of "c" & Performance \\
\hline$>0.85$ & Excellent \\
0.76 to 0.85 & Very good \\
0.66 to 0.75 & Good \\
0.61 to 0.65 & Medium \\
0.51 to 0.60 & Reasonable \\
0.41 to 0.50 & Poor \\
$\leq 0.40$ & Very poor \\
\hline
\end{tabular}

(vi) Method efficiency (EM) proposed by Zacharias et al. (1996)

$$
\mathrm{EM}=\frac{\sum_{i=1}^{n}\left(X_{i}-\bar{X}\right)^{2}-\sum_{i=1}^{n}\left(X_{i}-Y_{i}\right)^{2}}{\sum_{i=1}^{n}\left(X_{i}-\bar{X}\right)^{2}}
$$

(vii) Absolute average error (EAE)

$$
E A E=\frac{1}{n} \sum_{i=1}^{n}\left|X_{i}-Y_{i}\right|
$$

(viii) Absolute maximum error (EME)

$$
E M E=\operatorname{MAX}\left(\left|X_{i}-Y_{i}\right|\right)_{i=1}^{n}
$$

\section{RESULTS AND DISCUSSION}

Considering groups of 20 fruits, the mean time to obtain the manual measurements was one hour and for the digital measurements was 40 minutes. For the manual evaluation, the time spent was about 3 minutes per fruit, requiring two people to perform the activity; one of them performs the evaluation and the other annotates the results. In most cases these are recorded in field notebooks, with the need for these results be recorded to the computer for future statistical analysis. There is great manipulation of the results, which it can favor annotation and typing errors.

The total time spent by phenotyping using images is $2 / 3$ of the manual method, being performed by only one person through computational software with minimal manipulation of results, since the data is already recorded automatically. In cases where it is necessary to perform fruit evaluation in a short period of time, it becomes more efficient, since it is possible to identify and acquire the images with less than one minute per fruit, allowing the images to be stored for future evaluation, or implement automated phenotyping techniques. Results are similar to those obtained by Cortes et al. (2017), who reporte that phenotyping using digital images was three times faster than the manual option.

The values of correlation of Pearson were higher than 0.9973 for all the characteristics evaluated. According to Hopkins (2000), this indicates a correlation that is almost perfect; that is, there is a high degree of linear association between the two methodologies of evaluation. The good consistency between the two methodologies is very important; it allows one to generate information faster and is useful to improve harvesting, storage, packaging, transportation and commercialization activities (Cortes et al., 2017). 
The results of the method of index efficiency proposed by Zacharias et al. (1996), confirms an agreement between the results from the two methods studied, with values close to 1 (Table 3).

Table 3. Coefficient of Pearson correlation (r), concordance index (d), performance index (c) and the efficiency of the method (EM) for the comparisons between the measurements of winter squash fruits obtained manually and the measurements from the image analysis.

\begin{tabular}{lllll}
\hline Descriptors & r & d & c & EM \\
\hline Length of fruit & 0.9981 & 0.9748 & 0.9730 & 0.8845 \\
Diameter of fruit & 0.9986 & 0.9322 & 0.9309 & 0.6388 \\
Length of internal cavity & 0.9973 & 0.9762 & 0.9736 & 0.8889 \\
Diameter of internal cavity & 0.9979 & 0.9313 & 0.9292 & 0.6448 \\
\hline
\end{tabular}

The values of the concordance index proposed by Willmott et al. (1985), were higher than 0.9313 (Table 3). This index varies from zero, when there is no concordance, to one, when there is perfect concordance. Moreover, according to the criteria used by these authors, this indicates an excellent accuracy between the methods confronted. Results similar to these were obtained by Adami et al. (2008), and Martin et al. (2013), which concluded that the evaluation of the leaf area by digital images is an alternative to the traditional method, allowing for a more precise measurement of these characteristics.

The values of the performance index were higher than 0.9292 for all the characteristics and according to Camargo and Sentelhas (1997), this indicates that the evaluation of fruits based on images had an excellent accuracy of measurement. Therefore, it might be assumed that the evaluation of fruits based on images was equivalent to manual evaluation (Table 3). Similar results were found when estimating the leaf area of cotton, cashew, soybean, and corn, based on linear measurements and dry matter of leaves, with previous calibration of the digital images (Ramos et al., 2015). The method's efficiency indicated high precision between the manual and digital measurements of the morphological characteristics, ranging from 0.6388 to 0.8889 . These results show that phenotyping using images is accurate and can be used to replace traditional methodology.

The analysis of the Coefficient of Pearson correlation, concordance index, and indices of performance and efficiency of the method are frequently used to verify the similarity between two or more methodologies. This approach was used for comparing different phenotyping methods in soybean, where the new method had values similar to the usual method (Machado Juniorr, et al 2018). This approach has also been used for estimating parameters such as the reference evapotranspiration (Pereira et al., 2009; Bragança et al., 2010; Tagliaferre et al., 2012; Cunha et al., 2013) and leaf area (Adami et al., 2008; Martin et al., 2013).

The estimates of the angular coefficient of regression differed significantly from 1 by the $t$ test $(\alpha \leq 0.05)$ for all the descriptors (Figure 5). This indicates that the values observed in these characteristics, based on images, did not follow the ratio 1:1 in relation to the values obtained from the manual evaluation. The models obtained for each characteristic adjusted with a coefficient of determination higher than $93 \%$ (Figure 5), corroborating the values of correlation observed in Table 3. Similar results were found in studies involving 
the estimation of the volume of fruits in other Cucurbitaceae based on the analysis of digital images (Rashidi et al., 2009; Koc 2007).

It was observed that the averages obtained from the analysis of images resembled those obtained manually, showing a slight increase (Table 4). The positive values of bias, ranging from 0.11145 to 0.2324 corroborate this result, indicating that the evaluation based on images led to a slight overestimation in the measurements of the characteristics (Table 4).

A

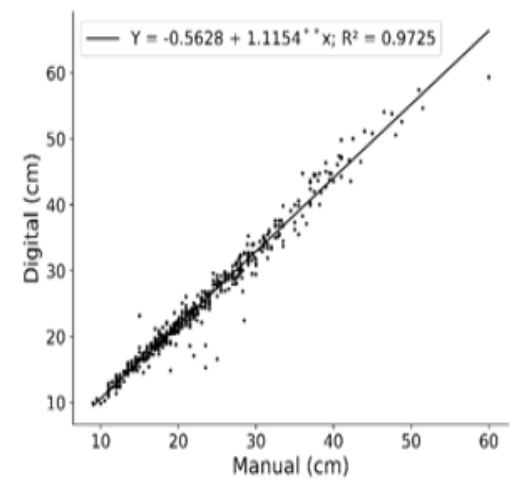

$\mathrm{C}$

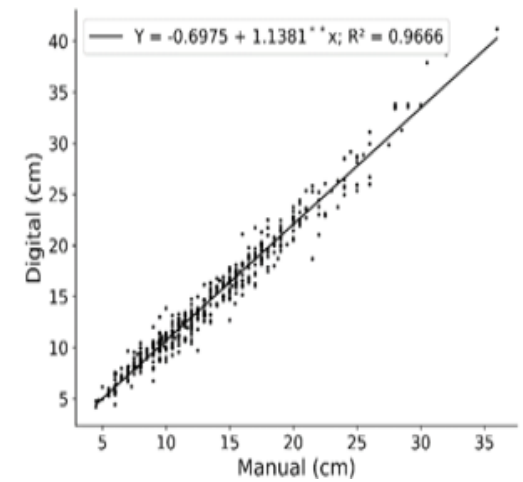

B

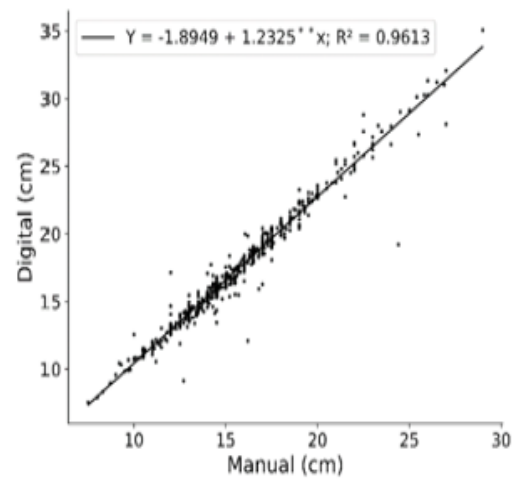

D

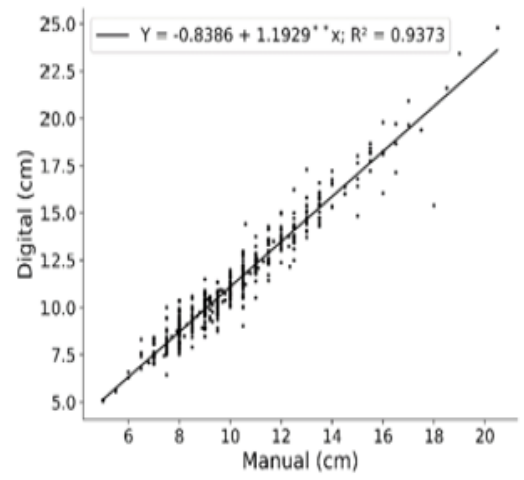

Figure 5. Dispersion of data obtained for the methodologies used in the measurement of winter squash fruits: $(x)$ manual evaluation and (y) analysis based on digital images: (A) Length of fruit; (B) diameter of fruit; (C) length of the internal cavity, and (D) Diameter of the internal cavity.

Table 4. Values of averages obtained from the manual evaluation and from the analysis of images in the characterization of fruits of winter squash accessions. Value of bias (Bias), absolute average error (AAE) and absolute maximum error (AME).

\begin{tabular}{llllll}
\hline \multirow{2}{*}{ Descriptors } & \multicolumn{2}{l}{ Averages (cm) } & \multirow{2}{*}{ Bias } & \multirow{2}{*}{ AAE (cm) } & \multirow{2}{*}{ AME (cm) } \\
\cline { 2 - 5 } & Manual & Digital & & & 8.81 \\
Length of fruit & 23.09 & 25.17 & 0.1145 & 2.29 & 6.31 \\
Diamter of fruit & 15.76 & 17.53 & 0.2324 & 1.84 & 7.39 \\
Length of internal cavity & 13.62 & 14.82 & 0.1379 & 1.40 & 4.42 \\
Diameter of internal cavity & 10.23 & 11.37 & 0.1920 & 1.19 & \\
\hline
\end{tabular}


Estimates of the absolute average error had a low magnitude ranging from 1.19 to $2.29 \mathrm{~cm}$ and the absolute maximum error ranged from 4.42 to $8.81 \mathrm{~cm}$ (Table 4). The estimates of errors increased at increasing the dimensions of the characteristics evaluated. It was possible to identify lower rates of absolute average error and absolute maximum error for the diameter of the internal cavity, 1.19 and $4.42 \mathrm{~cm}$, respectively. On the other hand, higher values of AAE $(2.29 \mathrm{~cm})$ and AME $(8.81 \mathrm{~cm})$ were observed for the length of the fruit. These higher estimates of errors were expected, considering that different people performed manual evaluations. The high estimates of AME are associated with fruits that have great morphological deformation (Figure 6), where it is difficult to maintain the same pattern between the two methods of phenotyping.
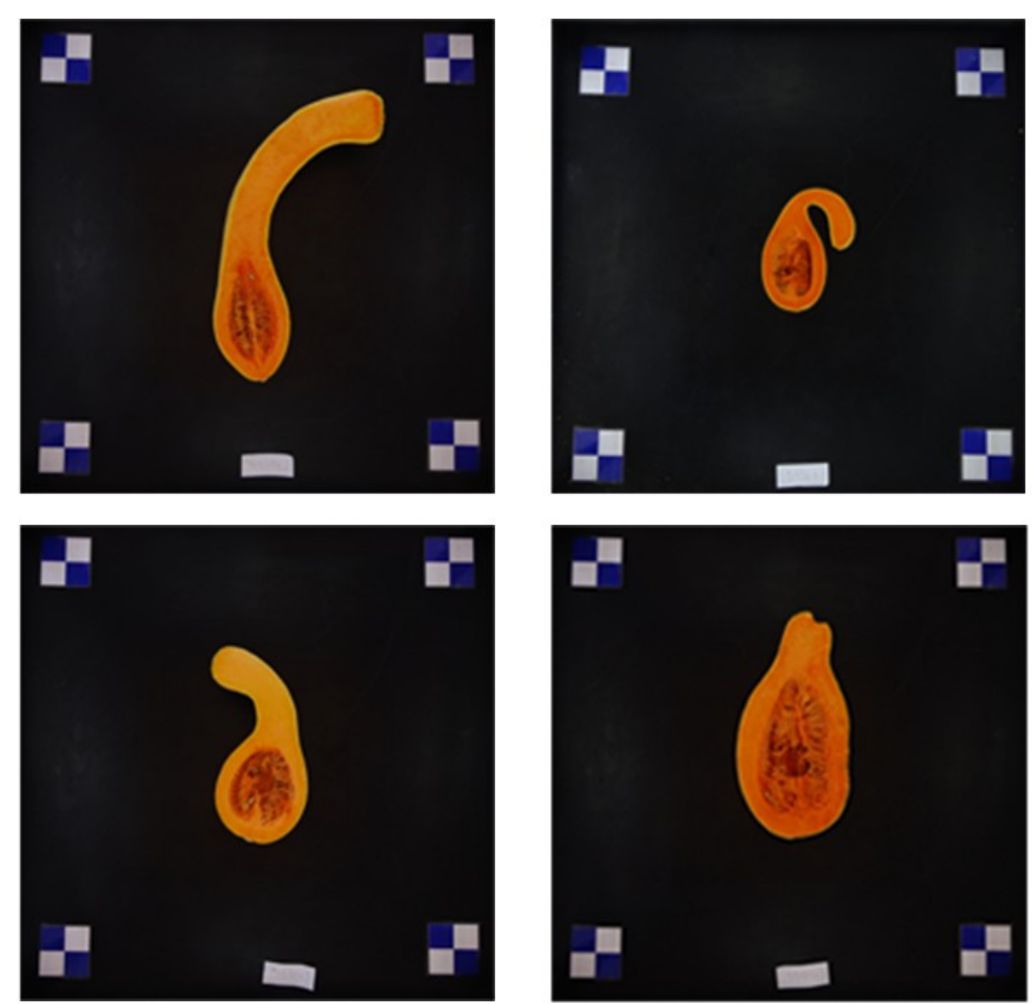

Figure 6. Morphologic variation observed in the evaluation of fruits of accessions of winter squash.

Studies involving measurements of fruits of papaya, orange, melon and watermelon by means of digital images also obtained low error for the characteristics diameter and length, showing that the measurements obtained with the use of digital images were similar to those measured manually (Koc, 2007; Khojastehnazhand et al., 2009; Rashidi et al., 2009; Cortes et al., 2017).

Variations between values in the two methodologies may have occurred due to the large number of fruits evaluated and a considerable morphological variability among the fruits (Figure 7). In this study, we evaluated 466 fruits from 148 accessions of C. moschata kept in the BGH-UFV, the commercial hybrids Tetsukabuto and Jabras and the cultivars 
Jacarezinho and Maranhão, which have fruits that can be classified in seven different classes. When evaluating the length and diameter of fruits in papaya, based on digital images, Cortes et al. (2017) obtained estimates of error equal to zero; however, they used only 50 fruits previously selected from the cultivar THB, which suggests fruits with great uniformity.

Another source of variation that may have contributed to the differences between the two methodologies is that the model used did not consider the variation in the distance between the photographic camera and the upper surface of the fruits which was altered according to the diameter of the fruit. This distance is inversely proportional to the diameter of the fruit. This type of variation was observed in a study involving the estimation of the volume of fruits of watermelon based on digital images (Koc, 2007). According to this author, the measures of volume were overestimated as the size of fruits increased. This problem can be solved by implementing methods of image processing as well as by adopting more complex algorithms capable of correcting this variation in the size of fruits (Khojastehnazhand et al., 2009). Another alternative to improve the acquisition of accurate images is by implementing a device that allows the adjustment of distance between the surface of the fruits and lens of the camera, so that the distance remains fixed regardless of the size of the fruit.

Considering that the evaluation of vegetable germplasm, in many cases is subject to errors of measurement, typing, and loss of information, the analysis based on digital images represents a promising approach for assisting this activity and can lead to a more efficient identification of superior genotypes. In addition, the acquisition and evaluation of plant germplasm in breeding programs provides advantages, allows storing of images for later use, and reduces the risk of human errors, by automating the process (Koc, 2007; Khojastehnazhand et al., 2009; Rashidi et al., 2009; Martin et al., 2013; Cortes et al., 2017). Easy implementation method, low cost, the images are captured with a conventional camera, which is simple, cheap and easy to handle. In addition, this methodology can be extrapolated to other crops and several variables (rind and pulp thickness, rind and pulp color, area and leaf volume, root and fruit estimates) and the images can be stored in a computer for later analysis, reduce workforce and time spent.

The expectation is that this technique will allow us to expand investigations, conducting phenotypic evaluation quickly and accurately, contributing to studies of genetic improvement. According to Cortes et al. (2017), image-based phenotyping can be used to facilitate genome-wide selection (GWS), genome-wide association studies (GWAS) and marker-assisted selection (MAS).

\section{CONCLUSIONS}

Fruit phenotyping based on digital images represents a promising alternative to characterize winter squash germplasm. This technique provided greater efficiency and high correlation manual evaluations.

\section{ACKNOWLEGDMENTS}

The authors would like to thank CAPES, CNPq, and FAPEMIG for granting the funding for the development of this project. 


\title{
CONFLICTS OF INTEREST
}

\author{
The authors declare no conflict of interest.
}

\section{REFERENCES}

Adami M, Hastenreiter FA, Flumignan DL and Faria RT (2008). Soybean leaflet area estimation using digital imagery and leaf dimensions. Bragantia. 67(4): 1053-1058. http://dx.doi.org/10.1590/S0006-87052008000400030.

Behera SK, Rath AK, Mahapatra A and Sethy PK (2020). Identification, classification \& grading of fruits using machine learning \& computer intelligence: a review. J. Ambient. Intel. Human. 1: 11. http://dx.doi.org/10.1007/s12652-02001865-8.

Bragança R, Reis EF, Garcia GDO and Pezzopane JEM (2010). Comparative study of the estimative evapoperspiration in reference to the wet period for three localities on the state of Espírito Santo. IDESIA. 28(2): 21-29. http://dx. http://dx.doi.org/10.4067/S0718-34292010000200003.

Camargo AP and Sentelhas PC (1997). Performance evaluation of different potential evapotranspiration estimating methods in the state of São Paulo, Brazil. Rev. Bras. Agrometeorol. 5: 89-97.

Cortes DFM, Catarina RS, Barros GBDA, Arêdes FAS, et al. (2017). Model-assisted phenotyping by digital images in papaya breeding program. Sci. Agric. 74(4): 294-302. http://dx.doi.org/10.1590/1678-992x-2016-0134.

Cruz CD (2013). GENES - a software package for analysis in experimental statistics and quantitative genetics. Acta Sci. Agron. 35(3): 271-276. http://dx. http://dx.doi.org/10.4025/actasciagron.v35i3.21251.

Cunha PCR, Nascimento JL, Silveira PM and Alves Júnior J (2013). Efficiency of methods for calculating class A pan coefficients to estimate evapotranspiration reference. Pesq. Agrop. Trop. 43(2): 114-122. http://dx.doi.org/10.1590/S1983-40632013000200005.

Ferreira MG, Salvador FV, Lima MNR, Azevedo AM, et al. (2016). Genetic parameters, dissimilarity and performance of pumpkin accessions. Hortic. Bras. 34: 537-546. http://dx.doi.org/10.1590/s0102-053620160413.

Fischer SZ, Barbieri RL, Peil RMN, Stumpf ERT, et al. (2015). Ornamental pumpkins: traits valued by consumers and floral designers. Hortic. Bras. 33: 480-487. http://dx.doi.org/10.1590/S0102-053620150000400012.

Fischer SZ, Barbieri RL, Peil RMN, Stumpf ERT, et al. (2016). Production and use of ornamental pumpkin landraces in the Rio Grande do Sul State, Brazil. Hortic. Bras. 34: 398-404. http://dx.doi.org/10.1590/S0102-05362016003015.

Gomes RS, de Almeida CF, Chagas RR, Júnior RM, et al. (2020) Winter squash (Cucurbita moschata D.) Displays Promising Nutritional Aspects in Fruits, Seeds and in the Seed Oil. J. Plant Biochem. Physiol. 8: 248. http://dx.doi.org/10.35248/2329-9029.20.8.248.

Gomes RS, Machado Junior R, de Almeida CF, Chagas RR, et al. (2020) Brazilian germplasm of winter squash (Cucurbita moschata D.) displays vast genetic variability, allowing identification of promising genotypes for agromorphological traits. PLOS ONE. 15(6): e0230546. https://doi.org/ 10.1371/journal.pone.0230546.

Hopkins WG (2000). Correlation coefficient: a new view of statistics. http://www.sportsci. org/resource/stats/correl.html (accessed 20 may 2020).

Khojastehnazhand M, Omid M and Tabatabaeefar A (2009). Determination of orange volume and surface area using image processing technique. Int. Agrophysics. 23(3): 237-242.

Koc AB (2007). Determination of watermelon volume using ellipsoid approximation and image processing. Postharvest Biol. Technol. 45(3): 366-371. http://dx.doi.org/10.1016/j.postharvbio.2007.03.010.

Machado Junior R, Alves GF, Gonçalves VAR, Oliveira SC, et al. (2018). Use of millimeter ruler as an alternative tool in the phenotyping of potential descriptors of soybean. Afr. J. Agric. Res. 13(28): 1425-1429. http://dx.doi.org/10.5897/AJAR2018.13248.

Machado Junior R, Gomes RS, Almeida CF, Alves FM, et al. (2017). Vegetable breeding as a strategy of biofortification in carotenoids and prevention of vitamin A deficiency. Afr. J. Agric. Res. 12(13): 1059-1066. http://dx.doi.org/10.5897/AJAR2016.11895.

Maeda H, Akagi T and Tao R (2018). Quantitative characterization of fruit shape and its differentiation pattern in diverse persimmon (Diospyros kaki) cultivars. Sci. Hort. 228: 41-48. http://dx.doi.org/10.1016/j.scienta.2017.10.006.

Martin TN, Marchese JA, Sousa AKF, Curti GL, et al. (2013). Uso do software ImageJ na estimativa de área foliar para a cultura do feijão. Interciencia. 38(12): 843-848. http://dx.doi.org/0378-1844/13/12/843-06 \$3.00/0.

Oliveira RL, Goncalves LSA, Rodrigues R, Baba VY, et al. (2016). Genetic divergence among pumpkin landraces. Semina Ciênc. Agrár. 37(2): 547-556. http://dx.doi.org/10.5433/1679-0359.2016v37n2p547.

Pereira DR, Yanagi SNM, Mello CR, Silva AM, et al. (2009). Performance of the reference evapotranspiration estimating methods for the Mantiqueira range region, MG, Brazil. Cienc. Rural. 39(9): 2488-2493. http://dx.doi.org/10.1590/S0103-84782009000900016.

Priori D, Barbieri RL, Mistura CC and Villela JCB (2018). Morphological characterization of pumpkin landraces (Cucurbita maxima) from Southern Brazil. Ceres. 65(4): 337-345. http://dx.doi.org/10.1590/0034737 X201865040006. 
Ramos FT, Ferreira LS, Pivetta F and Maia JCS (2015). Leaf blade area of different plants estimated by linear and dry matter measures, calibrated with the imagej software. Interciencia. 40(8): 570-575. http://dx.doi.org/0378$1844 / 14 / 07 / 468-08 \$ 3.00 / 0$

Rashidi M, Gholami M and Abbassi S (2009). Cantaloupe volume determination through image processing. J. Agric. Sci. Technol. 11: 623-631.

Resende GM, Borges RME and Gonçalves NPS (2013). Yield of pumpkin crop in different planting densities in the São Francisco Valley. Hortic. Bras. 31(3): 504-508. http://dx.doi.org/10.1590/S0102-05362013000300027.

Sidehabi SW, Suyuti A, Areni IS and Nurtanio I (2018). Classification on passion fruits ripeness using K-means clustering and artificial neural network. 2018 ICOIACT. 304: 309. https://doi. org/10.1109/ICOIACT.2018.8350728.

Silva DJH, Moura MCCL and Casali WD (2001). Genetic resources of the vegetable germplasm bank at the UFV, Brazil: historical background and assessment. Hortic. Bras. 19(2): 108-114. http://dx.doi.org/10.1590/S010205362001000200002.

Sousa CAF, Dias BBA, Martins PK, Molinari HBC, et al. (2015). New approach for plant phenotyping: concepts, current tools and perspectives. Rev. Bras. Geo. Física. 8: 660-672. http://dx.doi.org/10.1007/s10529-015-1861-x.

Tagliaferre C, Silva JP, Paula A, Guimaraes DUG, et al. (2012). Estimation of reference evapotranspiration for three locations in Bahia State, Brazil. Rev. Caatinga. 25(2): 136-143. http://dx.doi.org/10.15809/irriga.2012v17n1p28.

Walter A, Liebisch F and Hund A (2015). Plant phenotyping: from bean weighing to image analysis. Plant Methods 11(1): 14. http://dx.doi.org/10.1186/s13007-015-0056-8.

Willmott CJ, Ackleson SG, Davis RE, Feddema JJ, et al. (1985). Statistics for evaluation and comparison of models. $J$ Geophys. Res. 90(5): 8995-9005. http://dx.doi.org/10.1029/JC090iC05p08995.

Zacharias S, Heatwole CD and Coakley CW (1996). Robust quantitative techniques for validating pesticide transport models. Trans ASAE. 39(1): 47-54. http://dx.doi.org/10.13031/2013.27479.

Zaborowicz M, Boniecki P, Koszela K, Przybylak A, et al. (2017). Application of neural image analysis in evaluating the quality of greenhouse tomatoes. Sci. Hort. 218: 222-229. http://dx.doi.org/10.1016/j.scienta.2017.02.001. 